\title{
La utilización del discurso sobre la fe y lealtad del arzobispo Rodrigo Jiménez de Rada en la cancillería real de la Castilla Trastámara*
}

\author{
Pablo Martín Prieto ${ }^{1}$ \\ Universidad Complutense de Madrid \\ pablomartinprieto@ghis.ucm.es
}

RESUMEN: $\quad$ El discurso doctrinal sobre la fe y lealtad que el arzobispo Rodrigo Jiménez de Rada incluyó en el libro 7, capítulo 18 de su Historia Gothica sive De rebus Hispanie conocerá una difusión vernácula dentro de la corriente de traducciones de esta obra al castellano, como por ejemplo el Toledano romanzado. Con el éxito de la obra histórica del Toledano se puede relacionar la utilización que se hará del mencionado discurso sobre la fe y lealtad en el formulario de diplomas redactados en la cancillería real de Castilla durante la época Trastámara, destacando en dicha utilización la potenciación del sentido político del pasaje del arzobispo Rodrigo, reinterpretado en términos del programa ideológico de la monarquía.

\section{PAlabras ClaVE: Rodrigo Jiménez de Rada; De rebus Hispanie; fe; lealtad; cancillería; Castilla.}

\section{Usage of Archbishop Rodrigo Jiménez de Rada's discourse on faith and loyalty by the royal chancery in Trastámara Castile}

\begin{abstract}
The doctrinal discourse on faith and loyalty by Archbishop Rodrigo Jiménez de Rada in Book 7, Chapter 18 of his famous Historia Gothica sive De rebus Hispanie, underwent vernacular diffusion in a series of
\end{abstract}

* El presente trabajo se enmarca en los proyectos de investigación de la Secretaría de Estado de Investigación, Desarrollo e Innovación del Gobierno de España HAR2013-42211P: «Prácticas de comunicación y negociación en las relaciones de consenso y pacto de la cultura política castellana, ca. 1230-1504» y HAR2016-76174-P: «Expresiones de la cultura política peninsular en las relaciones de conflicto (Corona de Castilla, 1230-1504)».

1 ORCID iD: https://orcid.org/0000-0002-1451-2328. 
Castilian translations of this work, such as Toledano romanzado. The success of the Toletan Archbishop's historical work can be related to the use made of the aforementioned discourse on faith and loyalty in diploma formularies drafted by Castile's royal chancery in the Trastámara period. In this specific context, the political significance of Archbishop Rodrigo's discourse is emphasised, reinterpreting it in line with the ideological aims of the monarchy.

KEY WORDS: Rodrigo Jiménez de Rada; De rebus Hispanie; faith; loyalty; chancery; Castile.

CÓMO CITAR ESTE ARTÍCULO/CITATION: Martín Prieto, Pablo, «La utilización del discurso sobre la fe y lealtad del arzobispo Rodrigo Jiménez de Rada en la cancillería real de la Castilla Trastámara», Hispania, 78/260 (Madrid, 2018): 635-658. https://doi.org/10.3989/hispania.2018.014.

\section{INTRODUCCIÓN}

Dentro del amplio campo de estudio de los medios y los fines de la propaganda política orientada a representar y producir o reproducir y divulgar ideas e imágenes sobre el poder regio en tiempos medievales ${ }^{2}$, el estudio del trabajo de las cancillerías y de los formularios de aquellos diplomas que tienen al rey como autor jurídico reviste un interés propio ${ }^{3}$. Es indudable que en este contexto la «tecnología de la escritura ${ }^{4}$ se ha venido usando conscientemente al servicio de la promoción de una serie de valores y mensajes de naturaleza política, en la órbita de la difusión de lo que se ha podido llamar «ideología monárquica» ${ }^{5}$. Los preámbulos, así como otras fórmulas y partes del tenor diplomático, han podido ser estudiados como otros tantos cauces de aproximación al fenómeno del despliegue de la propaganda y difusión de concepciones sobre la realeza ${ }^{6}$, al tiempo que también han servido como vehículos de propagación de nociones e ideas relacionadas con otros dominios diversos dentro de la cultura de su época.

La evolución de los temas y motivos, así como de las formulaciones concretas de expresión de los mismos, sigue una lógica propia en el discurso de las cancillerías, oscilando entre los polos de la tradición y la innovación ${ }^{7}$; pero es obvio que el trabajo que se lleva a cabo en la cancillería no progresa en

2 CAMMAROSANO, 1994. AURELL, 2007.

3 GASSE-GRANDJEAN y TOCK, 2003.

4 ONG, 1982. GOODY, 1986.

5 ARIZALETA, 2010.

6 MARTÍN PRIETO, 29 (Madrid, 2016): 453-496.

7 MARTÍN PRIETO, 26 (Madrid, 2013): 209-244. 
el vacío, sino que en cada momento guarda relación con el contexto más amplio de las manifestaciones culturales de todo tipo imperantes en la sociedad de la que esta institución forma parte. Así, resulta de interés ahondar en las fuentes externas a la cancillería, de las que ocasionalmente ésta toma e incorpora ideas, nociones y formas de expresión. Sobre la base de estas premisas deseamos en el presente trabajo dirigir nuestra atención a la huella de cierto discurso del arzobispo toledano Rodrigo Jiménez de Rada que, desde las páginas de su Historia Gothica, gozará de una cierta difusión e influencia sobre otros escritos, hasta el punto de ser incorporado, en el siglo XIV, a los formularios de la cancillería real castellana de la forma que aquí se verá.

\section{EL DISCURSO DE LA FE Y LEALTAD EN LA OBRA DEL TOLEDANO}

La Historia Gothica sive De rebus Hispanie es, a qué dudarlo, la obra histórica más influyente de cara a la posteridad entre las compuestas por el arzobispo toledano Rodrigo Jiménez de Rada ${ }^{8}$, no sólo en virtud de su amplitud de enfoque panhispánico y la voluntad conscientemente ideológica con que fue concebida ${ }^{9}$, sino sobre todo por la circunstancia decisiva de que fuera seleccionada por Alfonso X como base para construir el marco narrativo de una parte substancial de la labor historiográfica por él impulsada (la Estoria de Espanna). Cuando el arzobispo Rodrigo narraba las dificultades y los peligros en que se vio envuelto el rey Alfonso VIII al comienzo mismo de su reinado, detuvo por un momento el relato de los hechos para componer, al hilo de la reflexión suscitada por éstos, un excursus de muy fina y cuidada elaboración retórica sobre la importancia central de la fe (fides) de cara a la realización y conservación del orden querido por Dios para Su creación, y de la noción próxima - pero distinta-, de fidelidad (fidelitas) como necesaria para hacer posible la vida del hombre en sociedad.

Este interesante discurso (en el capítulo 18 del libro $7^{\circ}$, De comendatione fidei seu fidelitatis, en adelante $\mathrm{DrH} 7.18^{10}$ ), verdadero «elogio de la fe y la fidelidad como valores que ordenan la cohesión del mundo» ${ }^{11}$, constituye un testimonio elocuente de las preocupaciones, inclinaciones y formación de su

8 GOROSTERRATZU, 1925. BALLESTEROS GAIBROIS, 1936. CASTRO ÁLAVA, 1968. GRASSOTTI, 55-56 (Buenos Aires, 1972): 1-302. ADRO, 1989.

9 LOMAX, 1977: 587-592.

10 FERNÁNDEZ VALVERDE, 1987: 240-241. Por una antigua convención respetamos la manera habitual de citar el texto, si bien parece que en origen la obra del Toledano no estaba dividida en libros, sino únicamente en capítulos: FERNÁNDEZ-ORDÓÑEZ, 26 (Lyon, 2003): 187-222.

11 MARTIN, 1992: 268. 
autor, tanto como uno de esos pasajes privilegiados de su obra donde, al aflorar de manera más abierta y viva el depósito de sus concepciones ideológicas, se puede tratar de discernir con mayor claridad algo de los propósitos que guiaban al Toledano en la selección y presentación de los materiales entretejidos en su compilación. Formada por derivación a partir de un mismo étimo, la pareja de términos fides/fidelitas y el campo semántico asociado se bifurcan en seguida para permitir el juego de dos conceptos relacionados pero separables: de un lado, la virtud teológica o teologal de la fe (fides), por medio de la cual la humanidad caída, massa dampnata, puede alcanzar la justificación reintegrándose a la vida de la gracia; de otro, la fidelidad (fidelitas) entre los hombres (hoy diríamos más bien «la mutua confianza»), sin mediación de la cual devendría imposible la vida en sociedad. Georges Martin ha mostrado que en su obra el arzobispo Rodrigo se vale tanto del término fides como del término fidelitas para hacer referencia a la noción de fidelidad, entendida desde el punto de vista social o político que puede relacionarse con las concepciones sobre obligación o compromiso que en la época gravitaban en torno al dominio de lo vasallático o feudal ${ }^{12}$.

Se ha supuesto que al concebir y realizar su obra, el arzobispo Rodrigo vino a plasmar un propósito ideológico propio dirigido a presentar a sus contemporáneos el reciente pasado del reinado de Alfonso VIII como una época de convergencia ideal por colaboración e identificación entre el rey y sus nobles; en la articulación del cuadro de esta «concordia modélica» ${ }^{13}$, la fidelidad habría de jugar necesariamente un papel importante, como noción que en su dimensión socio-política guarda una relación indudable con los valores feudales y la ética nobiliaria.

Al mismo tiempo y en paralelo, la dimensión teológica de la fe tampoco deja de transparentarse y hacerse presente en el pensamiento del Toledano (formado como teólogo en París) cuando en el referido discurso de $\mathrm{DrH} \mathrm{7.18}$ relaciona de manera flexible y potencialmente polisémica el marco de las obligaciones mutuas que sostienen el edificio de la vida social de los hombres entre sí con el de las obligaciones que el hombre tiene contraídas con su Creador. Se hace patente, a este respecto, ante todo una diferencia de cualidad en la articulación de las relaciones en juego, toda vez que la fe conecta al hombre con Dios y la fidelidad permite la interacción mutua de los hombres entre sí; pero no tanto una diferencia de posición necesariamente, ya que si bien la fidelidad entre los hombres puede darse entre iguales, desde el punto de vista de la ideología feudal este vínculo supone la desigualdad entre el su-

12 MARTIN, 1992: 262-270.

13 ARIZALETA, 26 (Lyon, 2003): 179. 
perior (señor) y el inferior (vasallo) ${ }^{14}$, del mismo modo como es vertical la relación de subordinación entre Dios y el hombre.

\section{FE Y FIDELIDAD EN LA TRADICIÓN DE LA CANCILLERÍA Y EN LA CULTURA CORTESANA}

Al objeto de valorar la medida en que el mencionado pasaje del Toledano puede haber llegado a influir en el discurso ideológico que se expresa en las fórmulas de la cancillería, conviene pasar revista, siquiera someramente, al empleo que en éstas se venía haciendo previamente de la pareja de conceptos fides/fidelitas, sin olvidar la posibilidad de relacionar dicho empleo con el tono y los temas de los escritos sapienciales, jurídicos y de espejos de príncipes elaborados en el entorno de la corte castellana.

La fe, entendida en su vertiente puramente teológica como virtud sobrenatural o en la acepción que equivale más genéricamente a confesión religiosa, no se puede decir que reciba en los diplomas de cancillería un tratamiento especial ni diferenciado respecto del uso habitual en cualquier otro contexto. En algunos diplomas regios de donación, se hace empleo de una antigua fórmula acuñada ${ }^{15}$ que pondera el valor de la ofrenda hecha por causa de piedad en relación con la fe del donante («quia omnis oblatio pro fidei quantitate et sincera pietate pensetur, non putamus esse minima que magna fides Deo consecratur») ${ }^{16}$. En ciertos preámbulos de notable elaboración retórica y teológica, con profusión de citas escriturarias, se menciona la relación de la fe con la piedad y los deberes morales del monarca, recogiendo consideraciones asimismo habituales, como por ejemplo cuando se recuerda la necesidad de fundar la fe sobre el cimiento de las buenas obras ${ }^{17}$. Otros documentos reales, en fin, alaban el compromiso de

14 En general, en las sociedades del llamado Antiguo Régimen, relaciones sociales que hoy se ven como mantenidas entre iguales reproducían el esquema vertical de una parte supeditada a otra: ejemplo típico de ello es el matrimonio. BROOKE, 1989. PASCUA y RODRÍGUEZ, 1999: 29-57. D'AVRAY, 2008.

15 Procede de la colección Formulae Visigothicae, no 9: ZEUMER, 1886: 579.

16 En diplomas de García I y Fernando I de León: LUCAS ÁLVAREZ, 1995, R-1, docs. $\mathrm{n}^{\mathrm{o}} 77,408,410,411,417$ y 421.

17 «... meminimus tamen nos mortalium conditione constringi, nec posse felicitatem future beatitudinis aliter promereri, nisi nos cultui et uere fidei deputemus [...]; pro qua re [...] prouidi esse debemus in his que de Deum sunt uel nostram spem augere et uere fidei fundamentum [...] ponere [...]», 960, abril 26, Sancho I hace una donación al monasterio de Sahagún: LUCAS ALVAREZ, 1995, R-1, doc. nº 231.

«... ipse Creator [...] operabitur [...] nisi fides eorum operibus decorata tantum sibi creditum cum fenoris usura Creatori suo unusquisque reddatur»: LUCAS ÁLVAREZ, 1993, regesto de Urraca, doc. $n^{\circ} 79$. 
las órdenes militares en la defensa de la fe ${ }^{18}$. Propiamente, nada hay en estas y otras menciones a la fe en los formularios de cancillería que permita reconocer una elaboración con caracteres propios del concepto dentro del vocabulario de lo que podríamos denominar propaganda regia.

En cambio, en los preámbulos diplomáticos y otras fórmulas ideológicamente significativas de los diplomas regios sí se puede observar un uso más frecuente y relevante del concepto de fidelidad. Se produce éste, sobre todo, en el contexto de afirmaciones sobre la conveniencia de que los reyes recompensen con concesiones graciosas a aquellos que se distinguen por dispensarles sus fieles servicios. La alusión a quienes sirven «(bien y) fielmente» a los monarcas es un lugar común muy difundido en todo el panorama de la diplomática europea. Fórmulas de preámbulo semejantes a: «Decet regiam potestatem aliquem sibi bene et fideliter seruientem donis remunerare» ${ }^{19}$ o derivadas de ella se relacionan directamente con modelos transpirenaicos ${ }^{20}$ y tendrán una larga vida entre las constantes del trabajo de cancillería, manteniéndose muy estables y reconocibles a lo largo del tiempo, incluso teniendo en cuenta los cambios derivados del paso del latín al romance. En algunos preámbulos se relaciona el deber que los monarcas tienen de premiar los servicios recibidos de sus fieles con las gracias que los mismos reyes reciben de $\operatorname{Dios}^{21}$; en otros se indica la conveniencia de estas recompensas a los fieles servidores para aumentar su celo en el servicio que realizan ${ }^{22}$; unas veces se relaciona

18 «Regali nempe conuenit maiestati quosque honestos ac religiosos uiros diligere, et eos maxime qui $[\ldots]$ seseque pro christiana fidei defensione murum et clipeum constanter opponere»: GONZÁLEZ, 1960, vol. 2, docs. nº 200 y 220.

19 Como muestra, valgan los siguientes diplomas de Alfonso VIII: GONZÁLEZ, 1960, vol. 2 , docs. $\mathrm{n}^{\mathrm{o}}$ 59, 64, 66, 69, 70, 73, 80, 86, 87, 92, 100, 109, 113, 150, 158, 179, 180, 182, $196,230,286$ y 296 , entre otros.

20 Formulae Imperiales, $n^{\circ}$ 18, 19, 27, 39 y 44: ZEUMER, 1886: 299, 300, 305, 316 y 320.

21 «Sicut benefitiorum Dei nec inmemores nec ingrati esse amonemus, sed innumeras gratiarum actiones omnipotenti Deo pro eis agere debemus, sic fidelium et obsequentium nostrorum seruitia remunerare habemus», 1114, julio 23, Urraca hace una donación a la iglesia de Mondoñedo: LUCAS ÁLVAREZ, 1993, registro de Urraca, doc. no 43.

22 «Regie conuenit serenitati, eos qui sibi fideliter seruiunt, donis remunerare, atque prediis et possessionibus ampliare, ut per hoc alii bonam spem de illo concipiant, et in eius seruitio ardentiores existant», 1132, mayo 29 y 1164, diciembre, Alfonso VII y Fernando II respectivamente hacen sendas donaciones a un particular: LUCAS ÁLVAREZ, 1993, registro de Alfonso VII, doc. $\mathrm{n}^{\mathrm{o}} 137$ y registro de Fernando II, doc. $\mathrm{n}^{\circ} 143$.

«Omne ius tam humanarum quam diuinarum legum hoc exigit, omnique rationi competit, ut que cum ratione fiunt rata habeantur, et quia mensura quisque, secundum uerbum euangelicum, mensus fuerit remercietur ei, ut quisque, scilicet, pro deuotius obsequiis et fidelibus seruiciis condignam retributionem recipiat, et ad seruiendum de cetero deuotior et fidelior existat», 1166, septiembre 29, Alfonso VIII hace una donación a la iglesia de Palencia: GONZÁLEZ, 1960, vol. 2, doc. $\mathrm{n}^{\circ} 88$. 
esta remuneración por los servicios recibidos con la liberalidad regia ${ }^{23}$; otras veces, con la exigencia de la justicia y de la razón ${ }^{24}$.

Esto, por lo que toca a las elaboraciones retóricas pensadas y reproducidas por los redactores de los diplomas que tienen al rey como autor jurídico: ya sean elaborados en el seno de la cancillería real cuando ésta mantiene una conformación y un funcionamiento regulares, o fuera de la misma, en diversos centros - principalmente scriptoria monásticos-, relacionados tantas veces con el servicio de la corona y la proyección hacia el exterior de la ideología monárquica ${ }^{25}$. Junto a esta importante faceta en el despliegue de la propaganda regia, es interesante tomar asimismo en consideración el contenido de una variedad de obras literarias (sapienciales, jurídicas, espejos de príncipes) que integran, de más lejos o cerca, el entorno de la cultura de la corte, cuyas concepciones y lenguaje contribuyen, en ocasiones de manera decisiva, a modelar.

Por ejemplo, a propósito de la fe, cabría observar una coincidencia en lo esencial entre dos cronistas coetáneos: Lucas de Tuy y Rodrigo Jiménez de Rada. Ambos mencionan el profesar o favorecer la fe católica (Tudense: fidem catholicam confitere; Toledano: zelare fidem) como uno de los pilares indispensables a lo que constituye su ideal de buen gobierno; el Tudense adorna la semblanza que hace de las virtudes de ciertos monarcas con el adjetivo pius (referido a Fernando I, Fernando II y Fernando III), adjetivo que también utiliza (referido a Fernando II) el arzobispo Rodrigo, quien añade la caracterización de Fernando I como rey temedor de Dios (timens Deum) ${ }^{26}$. Sin embargo, cuando se trata de la fidelidad, el arzobispo Rodrigo se destaca claramente, por la atención mucho más detenida que en sus obras concede a esta virtud ${ }^{27}$.

El romance castellano, para dar cuenta del término latino fidelitas, elige de preferencia verterlo como «lealtad», tenido por su equivalente, si bien no se

23 «Regie liberalitatis est fideliter sibi seruientibus digna rependere beneficia», 1173, septiembre 18, Artajona, Alfonso VIII hace una donación a un particular: GONZÁLEZ, 1960, vol. 2 , doc. $\mathrm{n}^{\mathrm{o}} 188$.

24 «Iustum et rationi conuenit ut qui regum seruiciis adherere elegerunt, amore regio sint fideles, et electi inter ceteros premia electorum condigna percipiant», 1187, junio 2, Burgos, Alfonso VIII hace una donación a un particular: GONZÁLEZ, 1960, vol. 2, doc. nº 473.

«Dignum est, et a rationis tramite non discordat, ut magestas regia dignam retributionem illis exibeat quos multiplicate fidelitatis obsequio apud se nouerit insignitos», 1230, mayo 25, Toledo, Fernando III hace una donación a la iglesia de Valladolid: GONZÁLEZ, 1983-1986, vol. 2, doc. $\mathrm{n}^{\circ} 267$.

25 MARTÍN PRIETO, 86 (Madrid, 2016): 577-618.

26 RODRÍGUEZ, 26 (Lyon, 2003): 134-136. FERNÁNDEZ GALLARDO, 12 (Alcalá de Henares, 2004): 53-119.

27 Sobre la relevancia de la fidelidad en la construcción del relato del Toledano: MARTIN, 26 (Lyon, 2003): 107-112. 
deriva de aquél, sino de legalitas (legalidad; de donde procede decir de una persona leal que es «de buena ley»). Así, en las fórmulas diplomáticas antes consideradas, el giro latino característico bene et fideliter (referido al servicio) dará paso a «bien» $e$ «lealmente» ${ }^{28}$. Es de notar, de pasada, que cuando en la época de la cancillería latina la redacción sugería una pareja de adverbios para significar la misma idea, pero el primero de ellos en lugar de ser bene era ya fideliter, la expresión se podía completar con legitime, adverbio que ya no dista mucho del «lealmente» de los documentos castellanos posteriores ${ }^{29}$.

En el ámbito de la primera literatura castellana, la «lealtad» recibirá prontamente carta de naturaleza y se abrirá paso en obras de todo género: véanse las alabanzas y comparaciones que se hacen de dicha virtud en el primer capítulo del Libro de los doze sabios o Tratado de nobleza e lealtad ${ }^{30}$; la caracterización que se hace de Fernando III, en el Setenario, como «derechurero e leal, tan bien en dichos como en fechos» ${ }^{31}$; las consideraciones sobre la lealtad como relacionada estrechamente con «verdad» y fieldad, en los Castigos de Sancho $I^{32}$, por no extendernos a sondear el empleo del término en las obras legislativas de Alfonso X (Espéculo, Partidas...), por ejemplo.

\section{LA RECEPCIÓN DEL DISCURSO SOBRE LA FE Y LEALTAD DEL ARZOBISPO RO- DRIGO EN LA HISTORIOGRAFÍA ROMANCE}

Como es bien sabido, el éxito de la Historia Gothica del Toledano propició tempranas versiones y adaptaciones de la obra en lenguas vernáculas. La Estoria de los godos del siglo XIII (Biblioteca Nacional, Madrid, ms. 302), la llamada «versión leonesa» que la continúa hasta la época de Alfonso X y se

28 «Porque entre todas las cosas que los reyes deven a fazer, sennaladamente estas dos les convienen mucho: la una, de dar gualardon a los que bien e lealmente los sirvieron», 1264, abril 29, Sevilla, Alfonso X confirma el libro del fuero a los concejos de la Extremadura: VELASCO BAYÓN, 2010, vol. 1, nº 21.

29 «Equitati et iustitie conuenit ut ei beneficiat unusquisque, qui sibi fideliter et legitime seruit», 1146, agosto 19, Toledo, donación de Alfonso VII a un particular: RASSOW, 10 (Leipzig-Berlín, 1928): 395.

30 WALSH, 1975.

31 VANDERFORD, 1945: 8.

32 GAYANGOS, 1860: «Tres cosas son las que al rey deben facer sus vasallos sobre todas las otras, las cuales son estas: la primera, amarle bien derechamente e guardarle fieldat, e verdat, e lealtad» (p. 106); «... las armas con que el rey ha de lidiar son la verdat e la lealtad; e las armas de los sus vasallos que han a lidiar por el son estas mesmas» (p. 110); «La lealtad es fija de la verdat», «la falsedat es contraria de la lealtad» (p. 153); «La lealtad e la verdat es tal como la buena triaca, e la traicion e la falsedat es tal como el tosico mortal. De la verdat e de la lealtad nascen todos bienes, e de la traicion e de la falsedat salen todos los males» (p. 170). 
recoge en el mismo códice que los Anales Toledanos III (Biblioteca Nacional, Madrid, ms. 10046), la llamada «versión completa de 1256» (pero que es del siglo XIV: Biblioteca Nacional, Madrid, ms. 684) y los dos manuscritos (ya del siglo XVI) del Toledano romanzado, texto del siglo XV (Real Academia de la Historia, Madrid, ms. 6511 y Real Biblioteca de El Escorial, ms. V-II5), entre otras copias y derivados, testimonian la amplia recepción que tuvo la obra histórica del arzobispo Rodrigo en castellano ya en época medieval ${ }^{33}$. Pero sin duda, la gran difusión del Toledano le vino de ser adoptado en el scriptorium de Alfonso X como marco narrativo de referencia (conjuntamente con el Chronicon mundi de Lucas de Tuy, pero dando preferencia a la obra del Toledano sobre el Tudense) para la gran compilación de la Estoria de Espanna. Una traducción de la Historia Gothica al castellano, muy posiblemente hecha en el seno del scriptorium alfonsí y quizá únicamente como instrumento de trabajo (es decir, no pensada para su difusión), es la base del relato de la Estoria de Espanna entre Alfonso VII y 1243, año de terminación de la obra (inconclusa) del Toledano ${ }^{34}$.

En consecuencia, la incorporación de parte substancial de la narración del arzobispo Rodrigo a la magna compilación historiográfica alfonsí (incluyendo los difíciles comienzos del reinado de Alfonso VIII, al hilo de los cuales el Toledano incluyó su mencionado discurso de la fe y lealtad) es clave para la difusión en romance de los hechos y las ideas de la Historia Gothica, en una cadena de transmisión que alcanza hasta el Toledano romanzado por antonomasia ya en los albores de la Modernidad ${ }^{35}$.

Conviene en este punto comparar la manera como algunos de estos textos en romance, más o menos influyentes de cara a la posteridad, recogen el discurso del Toledano. En la Estoria de Espanna, y más concretamente en el texto editado por Ramón Menéndez Pidal como Primera crónica general $(P C G)$, este discurso ocupa el capítulo 991 («El capitulo de la alabança de la fe et de la lealtad, et del puiar del rey») y se reporta así:

El arçobispo don Rodrigo de Toledo que fue, departe en este logar de la fe et de la lealtad, et dize assi: que ninguna cosa non es de mayor gloria nin de mayor preç que la fe et la lealtad. Et la fe et la lealtad una cosa quieren seer et en uno se tienen, pero con tanto departimiento como uso agora aqui pornemos: que esta palabra ' $\mathrm{fe}$ ' es dicha por aquello que creemos Padre et Fijo et Spiritu Sancto, et las cosas que a esto pertenesçen. Et deste nombre 'fe' uiene este otro nombre que dezimos 'fieldad' et 'fiell'; et aquel omne es fiel que guarda la fe a Dios et a los omnes et a su alma, et las cosas que la fe manda. Otrossi este nombre que dezimos 'lealtad' nasçe deste otro que dezimos 'ley', et otrossi 'leal'; et leal es aquel que guarda la ley a

33 CATALÁN, 1992: 79-80. JEREZ, 26 (Lyon, 2003): 223-239.

34 CATALÁN, 1992: 50-51.

35 CATALÁN y JEREZ, 2005. 


\begin{abstract}
Dios et assi et a los omnes, et lealtad es aquella guarda. Et fe es la creencia, et ley las buenas costumbres della; et fe es el bien, et ley es las buenas costumbres por o ell alma ua a aquel bien que es la fe. Por que dezimos que fe et fiel et fieldad, et ley et leal et lealtad, en uno se tienen et a un bien uan. Et dize aun sobresto ell arçobispo que ninguno non puede plazer a Dios que sin fe fuere. Et muchas otras razones aduze ell arçobispo que razona sobresto que dicho auemos de la fe et de la lealtad; mas, porque non pertenesçe a la estoria, dexamoslo nos, et tomamos et dezimos lo que ende cumple, et dezimos ende assi: que este don Alffonsso rey ninno criandosse como es dicho et fascas tollido de su regno, esta fe et esta lealtad andudo buscando fasta que ueno a tiempo de fallarla. Et fallola en los suyos; et por la fieldad et por la sabiduria dellos et por el buen donario del, con quien era Dios, cobro lo que perdiera et gano lo que non ouiera ${ }^{36}$.
\end{abstract}

Como se aprecia, en el texto de la $P C G$ la traducción del discurso de $\mathrm{DrH}$ 7.18 se limita a una paráfrasis amplificatoria de la primera frase del Toledano: («Quid fide gloriosius?» / «ninguna cosa non es de mayor gloria nin de mayor preç que la fe et la lealtad»), antes de introducir una disquisición orientada a deslindar los campos semánticos cruzados de «fe» y «lealtad», explicando el significado de ambos términos y la relación entre ambos conceptos, con intención de afirmar la equivalencia esencial entre una y otra ( «fe et fiel et fieldad, et ley et leal et lealtad, en uno se tienen et a un bien uan») en razón del fin común a que tienden. A continuación, el redactor da paso a la traducción de la segunda frase de $\operatorname{DrH} 7.18$ («Impossibile est Deo placere quempiam sine fide» / «ninguno non puede plazer a Dios que sin fe fuere» ${ }^{37}$ ), pero se desinteresa en seguida de continuar dando cuenta del resto del discurso del Toledano, descartándolo por entender que «non pertenesçe a la estoria».

Las Estorias del fecho de los godos son unos textos mixtos del siglo XV en cuya composición se completa la traducción castellana de la Historia Gothica con pasajes escogidos de la Estoria de Espanna alfonsín ${ }^{38}$. En una de estas versiones, recogida en un manuscrito (Biblioteca Nacional, Madrid, ms. 9559) publicado como Crónica de España en 1893 por el marqués de la Fuensanta del Valle (CODOIN, 105), se recoge con mayor amplitud la traducción del discurso de la fe y lealtad del Toledano, desde su comienzo hasta poco menos de la mitad del mismo ${ }^{39}$ :

36 MENÉNDEZ PIDAL, 1906, vol. 1: 671-672.

37 Cita de Hebreos 11, 6: «Sine fide autem impossibile est placere Deo».

38 CATALÁN, 1992: 231. HIJANO VILLEGAS, 20 (Alcalá de Henares, 2008): 211-242.

39 MARQUÉS DE LA FUENSANTA DEL VALLE, 1893: 445. 
TABLA 1

\begin{tabular}{|c|c|}
\hline De rebus Hispanie, 7.18 & BN ms. 9559 \\
\hline $\begin{array}{l}\text { Quid fide gloriosius? } \\
\text { Impossibile est Deo placere quempiam sine } \\
\text { fide, si prima gracia in iustificatione impii } \\
\text { fides a theologis predicetur et per hanc } \\
\text { dampnatus homo gracie redonatur. }\end{array}$ & $\begin{array}{l}\text { Cual cosa es mejor nin mas presciada que } \\
\text { lealtad e fe, non puede ser que ome plega a } \\
\text { Dios, e todos los dotores de la santa teologia } \\
\text { la fe ponen primeramente entre las virtudes } \\
\text { teologicas porque ese ome ha de salvar; }\end{array}$ \\
\hline & $\begin{array}{l}\text { e sant Pablo contando estas tres virtudes que } \\
\text { son fe, esperanza e caridad, la primera que } \\
\text { puso e escribio es la fe: en el ome malo e } \\
\text { pecador, por esta cobra la gracia que perdio. }\end{array}$ \\
\hline Quid fidelitate pocius appetendum? & $\begin{array}{l}\text { Non hay en el mundo cosa que mas ome deva } \\
\text { amar e cobdiciar que lealtad e ser fiel, }\end{array}$ \\
\hline $\begin{array}{l}\text { Cum enim sit utilis et honesta, } \\
\text { sine hac Deus, qui omnia potest, noluit } \\
\text { mundum regi, }\end{array}$ & $\begin{array}{l}\text { ca Dios, que todas las cosas puede e son en su } \\
\text { poder, non quiso que el mundo se gobernase } \\
\text { sin lealtad, }\end{array}$ \\
\hline quia si hec periret, homo homini non subesset & $\begin{array}{l}\text { ca si la fe e la lealtad peresciesen, nengun ome } \\
\text { non seria mandado nin obediente a otro, }\end{array}$ \\
\hline $\begin{array}{l}\text { nec quisquam ab alio tutus esset et conuictus } \\
\text { inter homines non adesset, }\end{array}$ & $\begin{array}{l}\text { nin seria un ome seguro de otro, e asy non se } \\
\text { llegaría un ome a otro. }\end{array}$ \\
\hline & $\begin{array}{l}\text { E pues sy los omes non se llegasen nin se } \\
\text { ayuntasen en uno, }\end{array}$ \\
\hline $\begin{array}{l}\text { set nec quisquam sufficeret sibi solus } \\
\text { igitur cuncta pro nichilo facta essent: }\end{array}$ & $\begin{array}{l}\text { ¿que seria del ome solo? Non valdria nada, } \\
\text { e todas las cosas serian criadas en balde. }\end{array}$ \\
\hline & $\begin{array}{l}\text { Pues para bevir un ome con otro, e ser un ome } \\
\text { seguro de otro, o ser un ome obediente a otro, }\end{array}$ \\
\hline fides itaque sit preuia omnibus, [...]. & $\begin{array}{l}\text { conviene que la fe e la lealtad ande adelante. } \\
\text { Esta fe e esta lealtad fizo al rey don Alonso } \\
\text { cobrar toda su tierra que le había tomado su tio } \\
\text { el rey don Ferrando de Leon, e cobrolo todo } \\
\text { con la fe e la lealtad de los suyos que le } \\
\text { ayudaron a ello [...]. }\end{array}$ \\
\hline
\end{tabular}

Como se ve por este cotejo, el texto de BN ms. 9559 se ciñe en algunos puntos al discurso del Toledano como traducción bastante fiel del mismo, y en otros es una adaptación más libre que se aparta de él, por ejemplo, para añadir esa consideración, cerca del comienzo, sobre el lugar de la fe entre las tres virtudes teologales según san Pablo. Sin llegar a la mitad del texto de DrH 7.18, el redactor de BN ms. 9559 da por concluido el discurso y retorna a la narración histórica aplicándolo, como el Toledano, a las estrechuras de los inicios del reinado de Alfonso VIII. Se puede decir que existe un equilibrio, en este texto de BN ms. 9559, entre consideraciones de naturaleza teológica «fe» y otras referidas al papel central de la «fidelidad»o «lealtad» para la estabilidad del orden social, sin desatender las primeras. 


\section{LA ADOPCIÓN DEL DISCURSO SOBRE LA FE Y LEALTAD DEL TOLEDANO EN LA CANCILLERÍA}

Como es bien conocido y se ha recordado más arriba, el concepto de fidelidad o lealtad forma parte del bagaje conceptual y retórico sobre el que se ha venido cimentando durante siglos el trabajo cada vez más ordenado y regular de la cancillería real de Castilla. No es mucho lo que se sabe sobre los métodos empleados en el seno de la cancillería para la selección y elaboración de temas y citas tomados de la tradición y, en general, de todo el universo de la cultura escrita de su tiempo. Resulta evidente que, a lo largo del tiempo, no sólo los hábitos de fraseología característicos y los rasgos de estilo que parecen conformar un auténtico «lenguaje de cancillería» han podido influir y de hecho han influido en la lengua escrita y aun en el habla de quienes manejaban o escuchaban con frecuencia los documentos producidos en ella; teniendo en cuenta esta posibilidad, resulta sencillo acudir a los mismos diplomas para hallar los retazos de redacción que luego se pueden buscar (y en su caso, descubrir) en las manifestaciones conservadas de la cultura escrita de la época. Más difícil se antoja realizar el proceso a la inversa: esto es, descubrir la huella de un autor o de un texto bajo alguna redacción de cancillería, cuando en el diploma en cuestión no se hace explícita la cita en cuestión. Dejando al margen la relativa sensación de mayor seguridad cuando se trata de citas bíblicas (debido a que las Sagradas Escrituras son un texto tan conocido como omnipresente en toda literatura y forma de expresión escrita en los tiempos medievales ${ }^{40}$ ), es difícil llegar a pisar terreno firme o libre de conjeturas cuando se trata de establecer la procedencia de un pasaje de un diploma en concreto, como tomado de una fuente extra-cancilleresca.

Por eso nos ha parecido tan interesante la posibilidad de descubrir la incorporación del discurso sobre la fe y lealtad del Toledano, traducido al romance, en ciertos diplomas de cancillería de la primera época Trastámara. Sin duda el arzobispo Rodrigo no es un autor sin vinculación con la cancillería en su época, pero su obra principal, el De rebus Hispanie (aunque sin duda su redacción se benefició enormemente de las investigaciones del Toledano sobre documentos de cancillería), se ha de considerar en principio como una obra independiente.

Para mejor valorar el efecto de contraste que supone la incorporación del discurso sobre la fe y lealtad del Toledano a la práctica de la cancillería, re-

40 «Il suffit de parcourir, du VIIIe au Xe siècle, les écrits les plus divers, traités de bon gouvernement, lettres, descriptions des cérémonies liturgiques, pour être frappé de la fréquence des citations bibliques»: DAVID, 1951: 24. «It is assuredly no exaggeration to say that the Bible was not only the most studied book, the most translated book, but also, and perhaps more so, the most heavily applied book»: ULLMANN, 1963: 181. 
sulta oportuno pasar revista a algunas fórmulas de preámbulo donde se hace referencia a la lealtad, situadas cronológicamente justo antes de que la fórmula basada en el texto del arzobispo Rodrigo haga su aparición. En un documento de 1353 en el que el rey Pedro notifica a Sevilla las razones por las que desposeyó a Alfonso Fernández Coronel de la villa de Aguilar, se menciona la necesidad de punir las faltas de aquellos que más obligados están a guardar la lealtad que se debe a la corona:

Porque de los reyes es, e al su estado pertenesçe, de estrannar e escarmentar los malos fechos e desaguisados que se fazen en su regno e su sennorio, e sennaladamiente aquellos que son contra el su estado e mengua del su sennorio real; e la pena que es dada a los malos e a los que en tal yerro caen es exienplo a los otros que lo oyen e lo vean e lo sabean, de se guardar de caer en tal yerro, e guarden por ello mas conplidamiente lealtat a que son tenudos de guardar a su rey e a su sennor ${ }^{41}$.

La primera huella del pasaje de $\operatorname{DrH} 7.18$ en la cancillería la observamos en el preámbulo de un privilegio dado en 1365 por el rey Pedro a la ciudad de León, cuya lealtad se pondera introduciendo algunas consideraciones de carácter general sobre esta virtud, que si bien no suponen traducción directa o romanceamiento del discurso del Toledano, sí guardan con él una relación clara:

Porque la cibdat de Leon es cabeza del regnado de Leon, et es cibdat muy antigua, do poblaron los godos et los reyes de Leon, por el qual regnado de Leon yo traigo en las mis armas sennal de Leon, et porque en todos los menesteres que recrecieron a los reyes de Castiella et de Leon la dicha cibdat de Leon sirvieron siempre muy lealmente, aventurando los cuerpos et los fijos et las mugeres et los algos por servicio de los reyes onde yo vengo et mio, et por defendimiento de los mis regnos; et porque todas estas cosas ficieron ellos por la naturaleza que ovieron siempre con los reyes onde yo vengo et conmigo; et porque de la naturaleza nace la lealtad, et como la lealtad es la mas noble et alta virtud que pueda seer en el home, et por ella es poblado et se mantiene el mundo, de lo qual plaze a Dios et a los reyes et a los otros principes et sennores con quien los homes han de vevir; et esta lealtad es siempre predicada por los theologos, porque asi como en ser los homes leales a Dios, non teniendo el corazon nin la imaginacion en otro ninguno sinon en Dios, son salvos, asi en ser los homes leales a su rey et a su sennor, non teniendo el corazon nin la imaginacion en otro sennor ninguno, son por ello para siempre bienaventurados ellos et los de su linage; et los reyes son abdebdados por ello de les fazer merced porque sean grandes et honrados en los sus regnos ${ }^{42}$.

En especial, destacan en este preámbulo el tono general de elaboración retórica, la referencia a la lealtad como necesaria para la supervivencia del

41 DÍAZ MARTÍN, 1997-1999, vol. 3, doc. nº 804.

42 RISCO, 1792: 407-408. 
mundo y a que es predicada por los teólogos, como los indicios que inequívocamente muestran el conocimiento del texto en cuestión del Toledano por el redactor de la cancillería, si bien la elaboración de la fórmula de este diploma es autónoma y no mera traducción, sino a lo sumo paráfrasis libre de un par de lugares de $\mathrm{DrH} 7.18$.

Sobre la base de este preámbulo de 1365 , ya en época Trastámara, se va a producir la incorporación plena del discurso del Toledano, añadiendo una traducción que lo sigue parcialmente pero de una manera bastante fiel y directa. Como testimonio de este siguiente paso contamos con sendos diplomas de Juan I y Enrique III: el primero, dado en las Cortes de Burgos el 20 de agosto de 1379, es el privilegio de concesión del señorío de Melgar de la Frontera a Pedro Fernández Cabeza de Vaca43; el segundo, dado en Valladolid el 15 de marzo de 1401, es la confirmación por Enrique III del mayorazgo de Juan de Ponte $^{44}$. La fórmula de preámbulo resulta extraordinaria en ambos casos, tanto por su longitud infrecuente como por su alto grado de elaboración retórica; el diploma de 1401 añade, al discurso sobre la fe y lealtad, otras muchas consideraciones distintas, viniendo a convertirse casi en una antología del arte del preámbulo diplomático en la cancillería de Enrique III. Al hilo de uno y otro, resulta interesante hacer el cotejo con el texto base del Toledano que siguen con mayor o menor libertad, así como el cotejo de ambas fórmulas, la de 1379 y la de 1401 , entre sí, al objeto de comprobar en primer lugar cuáles son las elecciones a las que se recurre en el proceso de romancear el discurso de $\mathrm{DrH} \mathrm{7.18}$, y en segundo lugar, en qué medida se puede considerar que ambos preámbulos, el de 1379 y el de 1401, son redacciones independientes entre sí.

TABLA 2

De rebus Hispanie, 7.18

Quid fide gloriosius? Impossibile est Deo placere quempiam sine fide, si prima gracia in iustificatione impii fides a theologis predicetur et per hanc dampnatus homo gracie redonatur. Quid fidelitate pocius appetendum?

\section{Preámbulo de Juan I, 1379}

Porque la lealtad es la mas noble e alta virtud que puede ser en el omne, porque por ella es poblado e se mantiene todo el mundo, de lo qual plaze a Dios e a los reyes e a los otros sennores con quien los omnes an a bevir. E esta lealtad es sienpre predicada por los theologos,

43 SUÁREZ FERNÁNDEZ, 1982, doc. nº 56.

44 CAÑAS GÁLVEZ, 2010, doc. $\mathrm{n}^{\circ} 57$. 
que asi como an de ser los omes leales a Dios e a su rey e a su sennor, non teniendo el coraçon en otro sennor alguno, son para sienpre bienaventurados ellos e los del su linaje, e Dios dales por ello buen gualardon, e los reyes e los sennores que son tenudos e adebdados por ellos de les fazer merçet e grandes en las migajas.

Cum enim sit utilis et honesta, sine hac Deus, qui omnia potest, noluit mundum regi,

E porque esta lealtad es muy provechosa e convenible a Dios e al mantenimiento del mundo, e aun Dios, que todas las cosas pudo, non quiso que el omne fuese governado nin mantenido sin ella.

E esta es una de las que El encomendo e fio de los reyes como a Sus justiçias, que tienen $\mathrm{Su}$ lugar en este mundo, e aun los derechos mayor ruega pusieron en escarmentar a los que fuesen

quia si hec periret, homo homini non subesset nec quisquam ab alio tutus esset et conuictus inter homines non adesset, set nec quisquam sufficeret sibi solus et ita congregatio hominum deperiret: igitur cuncta pro nichilo facta essent; fides itaque sit preuia omnibus,

per quam quilibet Deo placet, contra la lealtad que contra otro yerro alguno, porque si esta lealtad peresçiese, omne a omne non obedesçeria, porque non seria seguro uno de otro, e non seria en los omnes ninguno vençido nin menos provado; otrosi, ninguno non podria aprovechar a si solo: e por ende el ayuntamiento de los omnes e el poblamiento del mundo peresçeria, e las cosas que Dios crio serian nada. E por ende la lealtad pujo sobre todas las cosas del mundo

e las faze mantener cada una en su estado quel pertenesçe,

por lo qual cada uno plaze a Dios

qui est Dominus dominorum;

fidelitatem etiam circa inferiores tanquam pupillam occuli inuiolatam custodiat et e a su rey e a su sennor,

e es tenudo de guardar cada uno a su sennor, illesam.

Nunquam enim hereditatis eius tuta possessio uiolatur et eius negotiatio nunquam mercede fraudatur;

non est in ea labor sine premio,

nec est timor sine adiutorio;

occuli eius securi, frons uelari nescia non indigent uelamento; tuta in occulto, gloriosa in publico, iocunda inter amicos, nobilis inter odiosos,

probris infesta, laudibus graciosa

ab omnibus acceptatur, etiam ubi displicet, aprobatur.

asi como la vista de los ojos.

E en esta lealtad non cae trabajo sin gualardon,

e los ojos del leal son muy seguros en la su fruente, non an menester cobertura. E esta es muy segura en la poridat e muy plazentera en lo manifiesto, e muy alegre entre los amigos e muy noble entre los enemigos,

e de todos es pagada, e aun a los que pesa della es alabada,

Set et uiciorum monstruosa catherua fidelitatem abnuens, quam in se renuit, in aliis 
concupiscit; dignitate enim humane nature conspicua, non prono, set uultu incedit erecto et terras dedignata similis celestibus inuenitur. Quiescit securitate consciencie, roboratur spei magnitudine, tota pura, tota desiderabilis, tota utilis inuenitur. e fuelga con segurança e afirmase con grandeza: toda publica, toda deseosa, toda aprovechosa es fallada

entre todas las partidas del mundo.

Del cotejo del pasaje del Toledano con el preámbulo del privilegio de 1379 se pueden extraer algunas conclusiones: en primer lugar, el preámbulo omite la introducción en forma de interrogación retórica del arzobispo Rodrigo, precisamente la parte que con mayor frecuencia era incluida en obras historiográficas en romance (recuérdese que las dos primeras frases del discurso de $\operatorname{DrH} 7.18$ eran todo lo que sobrevivía del mismo en el texto de la $P C G$ ) y la parte más propiamente teológica, donde más se trasluce el modelo escriturario principal del pasaje, esto es, el discurso de san Pablo sobre la fe en el capítulo 11 de su Carta a los hebreos; en su lugar, el preámbulo del diploma de Juan I comienza con un texto sobre la lealtad inspirado en el Toledano pero tomado directamente de un formulario de la cancillería o del privilegio dado por el rey Pedro a León en 1365, al que más arriba hemos hecho referencia; a partir de ese punto, el preámbulo de 1379 va siguiendo en castellano el texto del Toledano, omitiendo alguna parte del mismo (sobre todo las dos secciones «Nunquam enim [...] fraudatur» y «Set et uiciorum [...] inuenitur») y añadiendo otras nuevas que no proceden del arzobispo Rodrigo.

Amén del comienzo, tomado del privilegio de Pedro I de 1365, las adiciones más significativas del preámbulo de 1379 al discurso del Toledano son: la sección «E esta es una de las que [...] yerro alguno»), donde se remarca el origen divino del poder regio («reyes [...] que tienen Su lugar en este mundo»), la naturaleza del rey como juez («reyes como a Sus justicias»), y el hecho de que las ofensas contra la lealtad debida son las más graves de todas las que se puedan cometer; y la muy significativa substitución que se da cuando, donde el arzobispo Rodrigo expresaba la primacía entre otras virtudes de la fe, «por la que cualquiera complace a Dios, que es el Señor de señores», el preámbulo de 1379 «traduce»: «por lo qual cada uno plaze a Dios, e a su rey e a su sennor». Especialmente, esta última alteración da el tono de la transformación del texto del Toledano que se ha operado al incorporarlo a la tradición viva de la cancillería en forma de preámbulo: se obscurece o queda en segundo plano, hasta cierto punto, el valor teológico o religioso muy marcado en el discurso original del arzobispo Rodrigo, para reinterpretarlo en términos más políticos, como corresponde a las intenciones de representación del poder monárquico inherentes a la retórica de un privilegio real. La traducción selectiva del original del Toledano, las supresiones y las adiciones, 
abundan en un proceso ya iniciado en el privilegio de 1365 cuando desaparece la «fe» y es reemplazada por la «lealtad»; ahora, en este nuevo preámbulo de 1379 que deja fuera el comienzo del Toledano y en su lugar recoge una redacción del privilegio de 1365, el valor teológico del discurso del arzobispo queda substituido por el valor político, y el discurso de la fe y lealtad reinterpretado dentro del molde de consideración, que especialmente interesa en el seno de la cancillería, de la lealtad como virtud política.

Desde un punto de vista más amplio, en el contexto de construcción y consolidación de la legitimidad buscada por el nuevo poder Trastámara, cabe observar la actuación de pautas útiles de actualización de los contenidos ideológicos vinculados a la representación y propaganda del poder monárquico aportados por la tradición anterior de la cancillería castellana y por una variedad de producciones culturales más o menos próximas a la corte ${ }^{45}$. No parece, por lo tanto, desatinado suponer que en la reutilización del referido pasaje del Toledano puedan haber mediado motivos concretos de índole propagandística al servicio de la exaltación de la naturaleza y las funciones de la corona, cuando se retoca el discurso original para hacer sobresalir la dimensión política sobre la estrictamente teológica del mismo, subrayando el origen divino y el papel como juez del rey, así como la necesidad de profesarle lealtad para complacerle, de análogo modo a como se ha de complacer a Dios con la fe (Hebreos 11, 6) según el texto del arzobispo Rodrigo.

A este respecto, entre los añadidos más reveladores que el preámbulo de 1379 hace al discurso del Toledano está vincular esa forma de complacer a Dios y al rey mediante el ejercicio de la lealtad, con la necesidad de que cada uno ocupe en el concierto social el lugar que le corresponde: la lealtad, se dice, sirve para mantener a cada cual en el «estado que le pertenece», lo que referido a un privilegio de constitución de un señorío cabe verosímilmente interpretar como una declaración de principios dirigida a la nobleza en el momento clave para la consolidación de la dinastía que supone el comienzo del reinado de Juan I, heredero de su fundador o instaurador. Algo que también puede ser objeto de una lectura particularmente significativa si se combina con la transparente intención de reivindicar al servicio de los Trastámara el discurso sobre la lealtad tal como se elaboró y redactó por la cancillería castellana «precisamente» en tiempos del monarca al que vinieron a destronar, reutilizando y reinterpretando aquellas consideraciones al efecto contenidas en el preámbulo del diploma de 1365 dirigido a la ciudad de León.

Cabe observar análoga pauta cuando en 1401 la cancillería de Enrique III encabeza un privilegio con un preámbulo inusualmente largo que también

45 Véase al respecto, por ejemplo, NIETO SORIA, 2006: 37-53. 
reproduce, romanceado, el discurso de $\mathrm{DrH} 7.18$, muy similar al del privilegio citado de 1379 , pero con diferencias que nuevamente puede resultar ilustrativo cotejar en detalle:

\section{TABLA 3}

\section{Preámbulo de Juan I, 1379}

Porque la lealtad es la mas noble e alta virtud que puede ser en el omne, porque por ella es poblado e se mantiene todo el mundo, de lo qual plaze a Dios e a los reyes e a los otros sennores con quien los omnes an a bevir. E esta lealtad es sienpre predicada por los theologos, que asi como an de ser los omes leales a Dios e a su rey e a su sennor, non teniendo el coraçon en otro sennor alguno, son para sienpre bienaventurados ellos e los del su linaje, e Dios dales por ello buen gualardon, e los reyes e los sennores que son tenudos e adebdados por ellos de les fazer merçet e grandes en las migajas.

E porque esta lealtad es muy provechosa e convenible a Dios e al mantenimiento del mundo, e aun Dios, que todas las cosas pudo, non quiso que el omne fuese governado nin mantenido sin ella.

E esta es una de las que El encomendo e fio de los reyes como a Sus justiçias, que tienen $\mathrm{Su}$ lugar en este mundo, e aun los derechos mayor ruega pusieron en escarmentar a los que fuesen contra la lealtad que contra otro yerro alguno,

porque si esta lealtad peresçiese, omne a omne non obedesçeria, porque non seria seguro uno de otro, e non seria en los omnes ninguno vençido nin menos provado; otrosi, ninguno non podria aprovechar a si solo: e por ende el ayuntamiento de los omnes e el poblamiento del mundo peresçeria, e las cosas que Dios crio serian nada.

E por ende la lealtad pujo sobre todas las cosas del mundo e las faze mantener cada una en su estado quel pertenesçe,

por lo qual cada uno plaze a Dios e a su rey e a su sennor,

e es tenudo de guardar cada uno a su sennor, asi como la vista de los ojos.

\section{Preámbulo de Enrique III, 1401}

Porque la lealtad es la mas noble e alta virtud que puede ser en el ome, que por ella es poblado e se mantiene todo el mundo, de lo qual plaze a Dios e a los reyes e prinçipes e sennores con que los omes an de vevir. E esta lealtad es predicada por los theologos, porque asi como an de ser leales a Dios e a su rey e a su sennor, non seyendo el coraçon nin la emaginaçion en contra, son por ello por sienpre loados e bienaventurados ellos e su linaje, e Dios dales por ello buen gualardon, e los reyes e los sennores son mas tenudos e adebdados por ellos de les fazer merçedes e darles galardones.

E esta lealtad es muy provechosa e convenible a Dios e al mantenimiento del mundo, e aun Dios, que todas las cosas pudo, non quiso quel ome fuese mantenido $\mathrm{e}$ governado sin ella.

E esta es una de las que El encomendo e fio de los reyes con las sus justiçias, que tienen Su lugar en este mundo, e aun los derechos mayor ruega posieron en escarmentar a los que fuesen contra la lealtad que contra otro yerro alguno que fiziesen,

porque si esta lealtad fallesçiese, de ome a ome non obedesçeria a su sennor nin seria seguro uno de otro, e non serian los omes ninguno vençido nin menospreçiado; otrosi, ninguno non podria aprovechar a si solo: e por ende, el ayuntamiento de los omnes e el poblamiento del mundo peresçeria, e las cosas que Dios crio serian para nada.

E por ende la lealtad puso sobre todas las cosas del mundo e las faze mantener cada una en el estado que pertenesçe.

E el que es leal luz e claridat paresçe entre los otros omes, e con tal plaze a Dios e a su rey e a su sennor e a las gentes,

e por tanto cada uno es tenudo de guardar a su rey e a su sennor lealmente, asi como a la vista e a la lunbre de sus ojos. 
E en esta lealtad non cae trabajo sin gualardon, e los ojos del leal son muy seguros en la su fruente, non an menester cobertura.

E esta es muy segura en la poridat e muy plazentera en lo manifiesto, e muy alegre entre los amigos e muy noble entre los enemigos, e de todos es pagada, e aun a los que pesa della es alabada,

e fuelga con segurança e afirmase con grandeza: toda publica, toda deseosa, toda aprovechosa es fallada entre todas las partidas del mundo.
E esta lealtad non cae trabajo sin galardon, e los ojos del leal son muy seguros en la su fruente, non an menester cobertura;

e esta mas segura en la poridat, e muy plazentera en lo manifiesto, e muy alegre entre sus amigos e noble entre los enemigos, e aun a los que pesa della es alabada

e fuelga con segurança e afirmase con grandeza: toda publica, toda deseosa es fallada entre todas las partidas del mundo.

Dejando a un lado las diferencias explicables por el proceso de la transmisión documental desde la producción del original hasta la publicación actual, salta a la vista por algunos detalles (supresiones e interpolaciones) que se trata de dos versiones distintas de un mismo texto base: no tanto quizás dos romanceamientos independientes del discurso del Toledano, cuanto dos versiones sucesivas incorporadas cada una a su diploma en un momento distinto y probablemente teniendo a la vista, pero no siguiendo escrupulosamente, una misma traducción castellana que hemos de suponer formaba parte del instrumental de la cancillería. Tras esta sección común, como se ha indicado, el preámbulo del privilegio de 1401 continúa aún un buen trecho, enlazando otras fórmulas habituales de los preámbulos de la época ${ }^{46}$.

A este respecto, no está de más recordar que la lealtad será un concepto habitualmente manejado en los formularios de la cancillería castellana en la

46 El resto del preámbulo reza: «E porque pertenesçe a los reyes e a su muy enobleçida e engrandeçida realeza enobleçer e onrar e previlegiar e heredar a los sus vasallos que bien e lealmente los sirven, amandolos e queriendolos e heredandolos en los sus regnos, e enobleçiendolos por las noblezas de los reyes, e por la lealtad e bondat dellos.

E porque entre todas las otras cosas que a los reyes es dado de fazer les es dado de fazer graçias e merçedes e donaciones a sus vasallos e heredarlos en los sus regnos por que sean mas onrados e ayan con que mejor se puedan mantener, e onrarlos e previlegiarlos e enobleçerlos.

E porque todas las cosas que en este mundo son fechas fenesçen quando El tiene por bien e quanto a la vida deste mundo, cada una a su tienpo e curso sabido, e non finca otra cosa que fin non aya salvo Dios, que nunca ovo comienço nin avra fin, e a semejança d'El ordeno los angeles de la corte çelestial, e como quier quiso que oviesen comienço, pero non quiso que oviesen fin, mas que durasen para sienpre, e asi como El es duradero, asi quiso que su regno durase para sienpre. E por ende todos los reyes se deven menbrar de aquel regno adonde an de ir a ver razon con lo que les Dios encomendo en este mundo, e por Quien regnan e Cuyo lugar tienen, por lo qual son tenudos de fazer graçias e ayudas e bien e merçed a los sus naturales e vasallos, quanto mas adonde se demanda con razon e con derecho.

E el rey que la faze a de catar en ello tres cosas: la primera, que merçed es aquella que le demandan; la segunda, que es el pro o el danno que por ende le puede venir si la faze; e la terçera, quien es aquel a quien ha de fazer la merçed, e como ge la meresçe o puede meresçer»: CAÑAS GÁLVEZ, 2010: 107-108. 
época Trastámara ${ }^{47}$, absorbiendo en propio beneficio, por así decirlo, todos aquellos precedentes del tema elaborados por la cancillería en otro tiempo con un criterio integrador, como se ha visto con el ejemplo de la reutilización del preámbulo sobre la lealtad del citado diploma de 1365 dirigido por el rey Pedro a la ciudad de León.

\section{CONCLUSIONES}

El ejemplo considerado nos permite atisbar cómo la cancillería real de Castilla podía proceder en algunos casos a incorporar al tenor diplomático de los documentos producidos en su seno, ideas, citas, e incluso préstamos de secciones enteras (en esta ocasión mediante traducción) procedentes de textos elaborados al margen del trabajo de la cancillería. No sólo la Biblia y los autores sagrados podían ser objeto de cita y reelaboración con destino a los formularios de los diplomas de cancillería, sino también diversos autores, como en este caso el arzobispo Rodrigo Jiménez de Rada, cuyo pasaje, especialmente reconocible y característico de su famosa Historia Gothica, vino a quedar entretejido en la redacción de los largos y ambiciosos preámbulos doctrinales que hemos visto.

Siendo el discurso original del Toledano un buen ejemplo de la formación teológica de su autor, así como un verdadero manifiesto que fácilmente rebasa el plano de la especulación teológica para adentrarse en consideraciones de profundas implicaciones políticas, con todo, existe en él un neto equilibrio entre una y otra vertiente: entre fides y fidelitas, por simplificarlas con la claridad de esa pareja de términos relacionados. Sobre la base de este discurso del arzobispo Rodrigo, que como hemos visto no fue desconocido en la transmisión vernácula de su obra y derivados historiográficos de la misma, la contribución reconocible de la cancillería al hacer suyo y reelaborar el texto del Toledano consistirá, ante todo, en reducir su valor teológico en la misma medida en que se desarrolla su valor político, produciendo así una verdadera reinterpretación del discurso original, en el marco de las consideraciones tradicionales y propias de la cancillería sobre la lealtad como virtud política.

47 Dos ejemplos, entre muchos otros que podrían aducirse: «A los reyes pertenesçe de onrar e fazer gracias e mercedes a las eglesias e a los perlados e cavalleros e omnes bonos del su sennorio, sennaladamente aquellos que bien e lealmente los sirven e se aventuran por ellos», 1369, junio 25, Toledo, Enrique II dona Talavera al arzobispo de Toledo: GARCÍA LUJÁN, 1982, doc. $\mathrm{n}^{\circ} 103$.

«... quanta lealtad e fiança fallamos en vos siempre de quanto afan e trabajo avedes pasado por nuestro serviçio», 1387, noviembre 20, Cortes de Briviesca: DÍEZ MARTÍNEZ, BEJARANO RUBIO y MOLINA MOLINA, 2001, doc. $\mathrm{n}^{\circ} 220$. 
Nos hallamos pues en disposición de apreciar cómo la ductilidad y fuerza asimiladora de que hacían gala los redactores de la cancillería era capaz de aprovechar, reorientar y transformar parcialmente una fuente o procedencia, incluso tratándose de un autor tan prestigioso y conocido, de acuerdo con los procedimientos discursivos y los fines de la propaganda regia. A este respecto, no resulta seguramente aventurado postular que la relectura y reinterpretación del discurso original del arzobispo Rodrigo, a la que se procedió en el seno de la cancillería castellana adaptándolo para utilizarlo en los preámbulos vistos, no estaba únicamente orientada a subrayar los aspectos más puramente políticos del mismo sobre su sentido teológico, sino que también se pudo modelar con la intención decidida de apoyar la exaltación y legitimación de la nueva dinastía Trastámara en el momento delicado de su primera sucesión, precisamente cuando en 1379 Juan I sucedió a Enrique II. En este momento de consolidación e institucionalización de la monarquía Trastámara, en circunstancias de pacificación peninsular todavía en alguna medida vacilante, podía parecer acertado, y en modo alguno superfluo, adaptar las consideraciones del Toledano sobre la centralidad de la lealtad de cara a la estabilidad del orden social — planteadas allí en los términos «feudales» de otra época-, ajustándolas a las nuevas necesidades de fortalecimiento del poder monárquico, en los preámbulos de documentos dirigidos a nobles, de quienes se venía así a requerir la renovación, perseverancia o reconducción a la fidelidad en beneficio del segundo Trastámara de Castilla.

\section{BiBLIOGRAFÍA}

Adro, Xavier, Rodrigo Jiménez de Rada. Estadista y artifice del siglo XIII, Barcelona, Casals, 1989.

Arizaleta, Amaia, «Ut lector agnosceret: discurso y recepción en la obra de Rodrigo Jiménez de Rada (primera mitad del siglo XIII)», Cahiers de linguistique et civilisation hispaniques médiévales, 26 (Lyon, 2003): 163-186.

Arizaleta, Amaia, Les clercs au palais. Chancellerie et écriture du pouvoir royal (Castille, 1157-1230), París, Les Livres d'e-Spania, 2010.

Aurell, Martin (ed.), Convaincre et persuader: communication et propagande aux XIIe et XIIIe siècles, Poitiers, Université de Poitiers, 2007.

Ballesteros Gaibrois, Manuel, Don Rodrigo Jiménez de Rada, Barcelona, Labor, 1936.

Brooke, Christopher N. L., The Medieval Idea of Marriage, Oxford, Oxford University Press, 1989.

Cammarosano, Paolo (ed.), Le forme della propaganda politica nel due e nel trecento, Roma-París, École Française de Rome, 1994.

Cañas Gálvez, Francisco de Paula, Colección diplomática de Santo Domingo el Real de Toledo. Documentos reales I. 1249-1473, Madrid, Sílex, 2010. 
Castro Álava, José Ramón, Don Rodrigo Ximénez de Rada, Pamplona, Diputación Foral de Navarra, 1968.

Catalán, Diego, La Estoria de España de Alfonso X. Creación y evolución, Madrid, Fundación Ramón Menéndez Pidal/Universidad Autónoma de Madrid, 1992.

Catalán, Diego y Jerez, Enrique, «Rodericus» romanzado en los reinos de Aragón, Castilla y Navarra, Madrid, Fundación Ramón Menéndez Pidal, 2005.

David, Marcel, Le serment du sacre du IXe au XVe siècle, Estrasburgo, Palais de l'Université, 1951.

D'Avray, David, Medieval Marriage: Symbolism and Society, Oxford, Oxford University Press, 2008.

Díaz Martín, Luis Vicente, Colección documental de Pedro I de Castilla 1350-1369, Salamanca, Junta de Castilla y León, 1997-1999.

Díez Martínez, José Manuel, Bejarano Rubio, Amparo y Molina Molina, Ángel Luis, Colección de documentos para la historia del reino de Murcia. XI. Documentos de Juan I, Murcia, Real Academia Alfonso X el Sabio, 2001.

Fernández Gallardo, Luis, «De Lucas de Tuy a Alfonso el Sabio: idea de la Historia y proyecto historiográfico», Revista de poética medieval, 12 (Alcalá de Henares, 2004): 53-119.

Fernández Valverde, Juan (ed.), Roderici Ximenii de Rada Historia de rebus Hispanie sive Historia Gothica, Turnhout, Brepols, 1987.

Fernández-Ordóñez, Inés, «La técnica historiográfica del Toledano. Procedimientos de organización del relato», Cahiers de linguistique et de civilisation hispaniques médiévales, 26 (Lyon, 2003): 187-222.

García Luján, José Antonio, Privilegios reales de la catedral de Toledo (1086-1462), Toledo, Caja de Ahorro Provincial de Toledo, 1982.

Gasse-Grandjean, Marie-José y Tock, Benoît-Michel (eds.), Les actes comme expression de pouvoir au Haut Moyen Age (Actes de la table ronde de Nancy, 26-27 novembre 1999), Turnhout, Brepols, 2003.

Gayangos, Pascual, Escritores en prosa anteriores al siglo XV, Madrid, M. Rivadeneyra, 1860.

González, Julio, El reino de Castilla en la época de Alfonso VIII, Madrid, Consejo Superior de Investigaciones Científicas, 1960.

González, Julio, Reinado y diplomas de Fernando III, Córdoba, Monte de Piedad y Caja de Ahorros de Córdoba, 1983-1986.

Goody, Jack, The Logic of Writing and the Organisation of Society, Cambridge, Cambridge University Press, 1986.

Gorosterratzu, Javier, Don Rodrigo Jiménez de Rada, gran estadista, escritor y prelado, Pamplona, T. Bescansa, 1925.

Grassotti, Hilda, «Don Rodrigo Ximénez de Rada, gran señor y hombre de negocios en la Castilla del siglo XIII», Cuadernos de Historia de España, 55-56 (Buenos Aires, 1972): 1-302.

Hijano Villegas, Manuel, «Estoria del fecho de los godos», Revista de literatura medieval, 20 (Alcalá de Henares, 2008): 211-242. 
Jerez Cabrero, Enrique, «La Historia Gothica del Toledano y la historiografía romance», Cahiers de linguistique et de civilisation hispaniques médiévales, 26 (Lyon, 2003): 223-239.

Lomax, Derek W., «Rodrigo Jiménez de Rada como historiador», en Actas del V Congreso de la Asociación Internacional de Hispanistas (Burdeos, 2-8 septiembre 1974), Burdeos, Université de Bordeaux-III, 1977: 587-592.

Lucas Álvarez, Manuel, El reino de León en la Alta Edad Media. V. Las cancillerías reales (1109-1230), León, Centro de Estudios 'San Isidoro', 1993.

Lucas Álvarez, Manuel, El reino de León en la Alta Edad Media. VIII. La documentación real astur-leonesa (718-1072), León, Centro de Estudios 'San Isidoro', 1995.

Marqués de la Fuensanta del Valle (ed.), Colección de documentos inéditos para la Historia de España. CV. Crónica de España del arzobispo D. Rodrigo Jiménez de Rada, Madrid, José Perales y Martínez, 1893.

Martin, Georges, Les juges de Castille. Mentalité et discours historique dans l'Espagne médiévale, París, Université de Paris-XIII, 1992.

Martin, Georges, «Noblesse et royauté dans le De rebus Hispaniae (livres 4 à 9)», Cahiers de linguistique et de civilisation hispaniques médiévales, 26 (Lyon, 2003): 101-121.

Martín Prieto, Pablo, «Invención y tradición en la cancillería real de Alfonso VIII de Castilla (1158-1214)», Espacio, Tiempo y Forma. Serie III: Historia Medieval, 26 (Madrid, 2013): 209-244.

Martín Prieto, Pablo, «Idea e imagen del rey en la diplomática medieval hispana: el valor de los preámbulos», Espacio, Tiempo y Forma. Serie III: Historia Medieval, 29 (Madrid, 2016): 453-496.

Martín Prieto, Pablo, «Representación y propaganda de la realeza en los preámbulos diplomáticos de León y Castilla hasta 1369», Anuario de Historia del Derecho Español, 86 (Madrid, 2016): 577-618.

Menéndez Pidal, Ramón (ed.), Primera crónica general. Estoria de España, vol.1, Madrid, Bailly-Bailliere, 1906.

Nieto Soria, José Manuel, «La monarquía como conflicto de legitimidades», en José Manuel Nieto Soria, (dir.), La monarquía como conflicto en la Corona castellano-leonesa (c.1230-1504), Madrid, Sílex, 2006: 13-71.

Ong, Walter, Orality and Literacy. The Technologizing of the World, Londres-Nueva York, Routledge, 1982.

Pascua, Ester y Rodríguez, Ana, «Nuevos contextos políticos en la sociedad pleno medieval: esposas y señoras en un mundo de jerarquía y fidelidad», en Anna Aguado (ed.), Mujeres, regulación de conflictos sociales y cultura de la paz, Valencia, Universitat de València, 1999: 29-57.

Rassow, Peter, «Die Urkunden Kaiser Alfons' VII. von Spanien», Archiv für Urkundenforschung, 10 (Leipzig-Berlín, 1928): 327-468 y 11 (1929): 66-137.

Risco, Manuel, Historia de la ciudad y corte de León y de sus reyes, Madrid, Blas Román, 1792. 
Rodríguez, Ana, «De rebus Hispaniae frente a la Crónica latina de los reyes de Castilla: virtudes regias y reciprocidad política en Castilla y León en la primera mitad del siglo XIII», Cahiers de linguistique et de civilisation hispaniques médiévales, 26 (Lyon, 2003): 133-149.

Suárez Fernández, Luis, Historia del reinado de Juan I de Castilla. Tomo II: registro documental (1371-1383), Madrid, Universidad Autónoma de Madrid, 1982.

Ullmann, Walter, "The Bible and Principles of Government in the Middle Ages», en La Bibbia nell'Alto Medioevo, Spoleto, Centro Italiano di Studi sull'Ato Medioevo, 1963: 181-227.

Vanderford, Kenneth H. (ed.), Alfonso el Sabio. Setenario, Buenos Aires, Universidad de Buenos Aires, 1945.

Velasco Bayón, Balbino, Herrero Jiménez, Mauricio, Pecharromán Cebrián, Segismundo y Montalvillo García, Julia, Colección documental de Cuéllar (934-1492), Cuéllar, Ayuntamiento de Cuéllar, 2010.

Walsh, John K. (ed.), Libro de los doze sabios o Tractado de la nobleza y lealtad, Madrid, Real Academia Española, 1975.

Zeumer, Karl (ed.), Formulae Merowingici et Karolini aevi, Hannover, Monumenta Germaniae Historica, 1886.

Recibido: 01/09/2017

Aceptado: 23/04/2018 